\title{
Study on the selection of vegetation for ecological restoration of residual soil slopes in South China
}

\author{
Wang De-yong ${ }^{1,2,3, *}$, Hu Jun-long ${ }^{1}$, Wang Jing ${ }^{1,2,3}$, Zun Qingjun ${ }^{1,2}$ \\ ${ }^{1}$ CCCC Fourth Harbor Engineering Institute Co., Ltd. Guangzhou 510230, China.
}

${ }^{2}$ Key Laboratory of Environmental Protection \& Safety of Communication Foundation Engineering, CCCC, Guangzhou 510230, China.

${ }^{3}$ Southern Marine Science and Engineering Guangdong Laboratory, Zhuhai 519082, China

\begin{abstract}
Vegetation selection is one of the key contents of slope ecological restoration, based on the characteristics of climate and soil in South China and the principle of local conditions, this paper studies the selection of vegetation in the ecological restoration project of the residual soil slope. The typical herbs, shrubs and trees suitable for the area are determined by theoretical analysis. At the same time, through field tests, the growth and development of vegetation after the spraying are monitored for a long time, and the interaction relationship between vegetation community after multiple vegetation mix-ups is analyzed. The results show that plant selection should avoid the choice of a single plant, and should try to achieve complementary coordination between species. At the same time, when taking a variety of plant mixing spray, the configuration ratio of different plants should be determined according to the growth cycle of different plants and the results of indoor ratio test, so as to avoid mutual interference.
\end{abstract}

\section{Introduction}

The construction of mountainous highway is often accompanied by a large number of high filling and deep excavation due to topography, forming many exposed engineering slopes. Because of the one-sided pursuit of economic benefits or technical limitations in the early engineering construction projects, most of the above exposed slopes were not treated with ecological restoration works, so that the original ecological system where the project is located has been damaged, and even lead to a large area of ecological degradation and aggravated soil erosion on the surface at the same time.

Since the 1990s, Chinese engineers have gradually realized the above-mentioned problems, and have successively introduced and independently developed a variety of slope ecological restoration technologies from abroad and applied them to domestic road construction projects, such as hydraulic spraying technique, externalsoil spray seeding technique and vegetation-growing concrete technique, etc. ${ }^{[1]}$. The so-called slope ecological restoration technology refers to the artificial means to create a suitable substrate for vegetation growth on the slope surface, build a vegetation community adapted to the environment, and slowly restore the slope vegetation. On the one hand, the slope ecological restoration technology uses the hydrological effect of vegetation to greatly reduce the soil erosion of the slope. On the other hand, it can restrain the expansion of the ecologically degraded area and avoid a greater ecological crisis. In addition, it can also improve the landscape image along the highway.

Vegetation selection is one of the core contents of the slope ecological restoration work, and its purpose is to build a long-term stable ecological community on the slope through the selection and matching of suitable vegetation species. Zhang and $Z_{\text {hou }}{ }^{[2]}$ proposed 7 principles for the selection of slope protection vegetation. At the same time, in terms of plant screening methods, it is mainly based on empirical induction ${ }^{[3]}$, analytic hierarchy process(AHP) ${ }^{[4]}$ and other methods to comprehensively screen slope protection vegetation, such as $\mathrm{Chen}^{[5]}, \mathrm{Xie}^{[6]}$ Liu $^{[7]}$ pointed out that grass species such as Eragrostis, Bermuda grass, Bahia grass and ryegrass are ideal grass species suitable for local site conditions. $\mathrm{Wei}^{[8]}, \mathrm{Guo}^{[9]}, \mathrm{Wu}^{[10]}$ screened tall fescue, bluegrass, ryegrass, lespedeza and other vegetation species suitable for ecological restoration in the subtropical region of southwest China. At present, the vegetation community configuration models explored and applied to slope ecological restoration at home and abroad mainly include: (1) herb mixed sowing; (2) herb and shrub mixed sowing; (3) arbor and legume mixed sowing; (4) arbor, shrub and herb mixed sowing ${ }^{[1-15]}$.

There are a large number of highways in the mountainous areas of South China. For this area, it has its own unique climate, soil and vegetation conditions. When selecting vegetation types, it is necessary to carry out targeted research based on the principle of "adapting measures to local conditions". Based on the investigation

\footnotetext{
*Corresponding author: de_yong_wang@163.com
} 
of the climatic and soil conditions in South China, this paper conducts a comprehensive analysis of the optimal vegetation for the ecological restoration of the residual soil slope in the area. At the same time, it conducts field experiments to study the restoration of the vegetation community under natural conditions. The selection of vegetation types in the ecological restoration of residual soil slopes has certain reference value.

\section{Climate and soil conditions in South China}

\subsection{Climatic conditions}

The mountainous area of South China is a subtropical semi-humid climate zone, with a mild and humid climate and plenty of sunshine. Such as Guangzhou, the area is rich in precipitation and concentrated in April to September. The annual average precipitation is about $1500 \mathrm{~mm}$, the annual maximum precipitation is above $2000 \mathrm{~mm}$, the annual minimum precipitation is about $900 \mathrm{~mm}$. And the annual average evaporation is about $1400 \mathrm{~mm}$.

At the same time, there are frequent typhoons in this area, with the maximum instantaneous wind speed reaching $17 \mathrm{~m} / \mathrm{s}$.

\subsection{Topography}

The northern mountainous area of Guangzhou belongs to the Nanling mountain system. The terrain is complex and the canyons are developed. The main areas are tectonic denudation and erosion of low mountains and hilly landforms in South China. The terrain is generally high in the middle and low at both ends, and the elevation is between $27 \mathrm{~m}$ and $492 \mathrm{~m}$. Regional landforms can be roughly divided into alluvial-proluvial accumulation landform units and structural denudation and erosion hilly landform units according to their genesis, as shown in Fig.1.

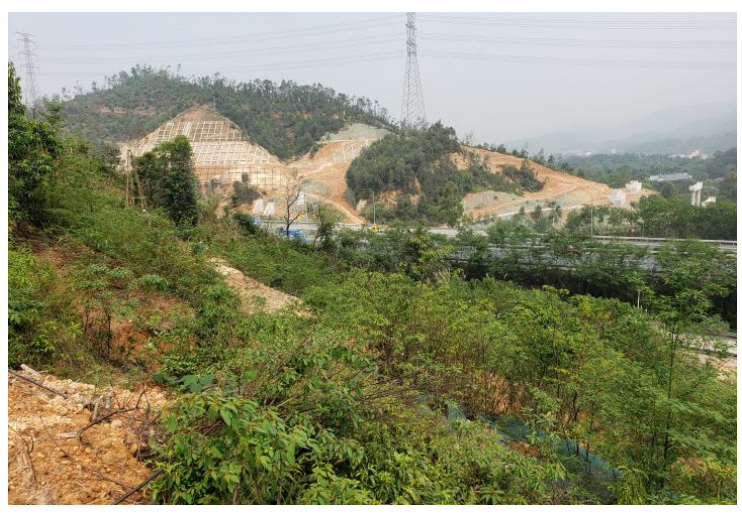

Fig.1. Typical topographic and geomorphic units in the mountains of South China

\subsection{Granite residual soil}

The granite residual soil is widely distributed in the mountainous areas of South China, and some low hills are exposed directly or under the thin slope soil. The thickness is not high, generally $3-10 \mathrm{~m}$. Granite residual soil can generally be divided into cohesive soil, sandy cohesive soil, and gravel cohesive soil from top to bottom, and its physical and mechanical characteristics are quite different in the vertical direction. Indoor geotechnical tests are carried out on typical granite residual soil samples in this area, and the basic physical index parameters are shown in Table 1.

Table 1. Physical index parameters of typical granite residual soil

\begin{tabular}{cccccc}
\hline Area & $\begin{array}{c}\text { specific } \\
\text { gravity }\end{array}$ & $\begin{array}{c}\text { Liquid } \\
\text { limit } \\
(\%)\end{array}$ & $\begin{array}{c}\text { Plastic } \\
\text { limit } \\
(\%)\end{array}$ & $\begin{array}{c}\text { Dry } \\
\text { density } \\
(\mathbf{g} / \mathbf{c m 3})\end{array}$ & $\begin{array}{c}\text { Moisture } \\
\text { content } \\
(\%)\end{array}$ \\
\hline $\begin{array}{l}\text { South } \\
\text { China }\end{array}$ & 2.74 & 33 & 25 & 2.6 & 18.8 \\
\hline
\end{tabular}

\section{Selection of ecological restoration vegetation}

\subsection{Principles of vegetation selection}

Based on the special topography and climatic soil conditions of the mountainous area of South China, such as hilly landforms, high temperature and rain, frequent typhoons, etc., combined with the characteristics of the engineering slopes in this area, this paper determines the basic principles of vegetation selection in this area as follows:

(1) Plants need to adapt to the climate of the area;

(2) Plants need to be resistant to barrenness and extensive management;

(3) Plants have a long green period and are perennial, which can make full use of hydrothermal conditions;

(4) Plant seeds germinate quickly and can form a developed root system in the early stage;

(5) The plant root system has strong resistance to pulling out, and the windward area of the canopy should not be too large;

(6) In combination with local vegetation survey, try to choose native plants that adapt to the local environment.

\subsection{Optional vegetation for ecological restoration}

Herbaceous plants are pioneer plants for slope protection. They have the advantage of rapid growth and coverage. They can form a more comprehensive protection for the slope in the early stage of the slope restoration project, and greatly reduce the hydraulic erosion and soil erosion of the residual soil slope.

Combining the characteristics of high temperature and humidity in the mountainous areas of South China, the herbaceous vegetation for ecological restoration in this area should be mainly perennial herbaceous plants that love warmth, tolerate flooding, tolerate barrenness, and have strong adaptability, such as Bermudagrass, Zoysia japonica, Fake grass, Bahia grass and so on. In addition, the above-mentioned vegetation can form an intricate root system network within a depth of $30 \mathrm{~cm}$, and the multisurface slope soil forms a reinforcement effect, which 
greatly reduces the probability of the surface residual soil slipping after being softened by water. At the same time, engineering experience shows that the ecological restoration of slopes based on a single vegetation is imperfect, and it is prone to degradation in the later growth process.

Compared with herbaceous plants, shrub and arbor plants have longer root systems, and their root tips can extend to the soil parent material and weathered layer, forming a good reinforcement for shallow soils. At the same time, shrub and arbor vegetation has a good advantage of drought resistance, wind sand prevention, dust reduction, fast growth, barren tolerance, and low environmental requirements. Therefore, the ecological restoration of the slope should also be matched with certain shrubs and arbor. The selected shrubs are mainly tropical and subtropical plants that like sunlight, warm and humid climate, and are resistant to water and humidity, such as Oleander, Albizia julibrissin, Schefflera. At the same time, considering the frequent typhoons in summer and autumn in this region, the choice of trees should avoid choosing tall and large perennial trees with a large canopy windward area.

In summary, according to the vegetation survey and literature research in this area, combined with the characteristics of South China, the main ecological restoration plants in this area are determined as shown in Table 2.

Table 2. Slope protection plants commonly used in South China

\begin{tabular}{|c|c|c|}
\hline Category & Family name & Scientific name \\
\hline \multirow{4}{*}{ Herbs } & Gramineae & $\begin{array}{c}\text { Cynodon dactylon, Zoysia } \\
\text { japonica, Eremochloa ophiuroides, } \\
\text { Paspalum notatum, Eragrostis } \\
\text { curvula, Vetiveria zizanioides, } \\
\text { Melinis minutiflora }\end{array}$ \\
\cline { 2 - 3 } & Leguminosae & $\begin{array}{c}\text { Crotalaria pallida, Melilotus } \\
\text { officinalis, Medicago sativa }\end{array}$ \\
\hline \multirow{4}{*}{ Shrubs } & Leguminosae & $\begin{array}{c}\text { Lespedeza bicolor, Magnolia } \\
\text { multiflora, Cajanus cajan }\end{array}$ \\
\cline { 2 - 3 } & Rhododendronaceae & Rhododendron ovatum \\
\cline { 2 - 3 } & Rosaceae & Rosa multiflora, Rosa laevigata \\
\cline { 2 - 3 } & Araliaceae & Schefflera octophylla \\
\cline { 2 - 3 } & Sapindus & Dodonaea viscosa \\
\cline { 2 - 3 } Trees & Leguminosae & Leucaena leucocephala \\
\cline { 2 - 3 } & Lythraceae & Lagerstroemia indica \\
\cline { 2 - 3 } & Anacardiaceae & Rhus chinensis \\
\hline \multirow{4}{*}{} & &
\end{tabular}

\section{Field test of vegetation selection}

\subsection{Overview of the test area}

The field test is carried out based on the Kaichun Expressway project. The annual rainfall in the area of the project reaches $2400 \mathrm{~mm}$, and the area where the project is located is affected by typhoons throughout the year. Heavy rains are frequent, the slope of the project is severely eroded, and the problem of soil erosion has become a more prominent problem in the project.

The test was carried out on the K5 slope which is protected by concrete lattice, and has a slope of $40^{\circ} \sim 60^{\circ}$. The slope is excavated in three levels, and the test area is the first level slope, as shown in Figure 2. The area within the red line in the figure is the test area, with a total area of about $3000 \mathrm{~m}^{2}$.

During the 9-month construction period of the on-site spraying, the temperature and precipitation on the site were monitored, as shown in Fig. 3 and Fig.4, respectively. The area where the project is located has a typical subtropical monsoon climate. The dry season is from December to April of the following year, with low precipitation. During the rest of the year, precipitation is abundant, and the frequency of heavy rain and heavy rain events is high. The maximum daily rainfall reaches $280 \mathrm{~mm}$.

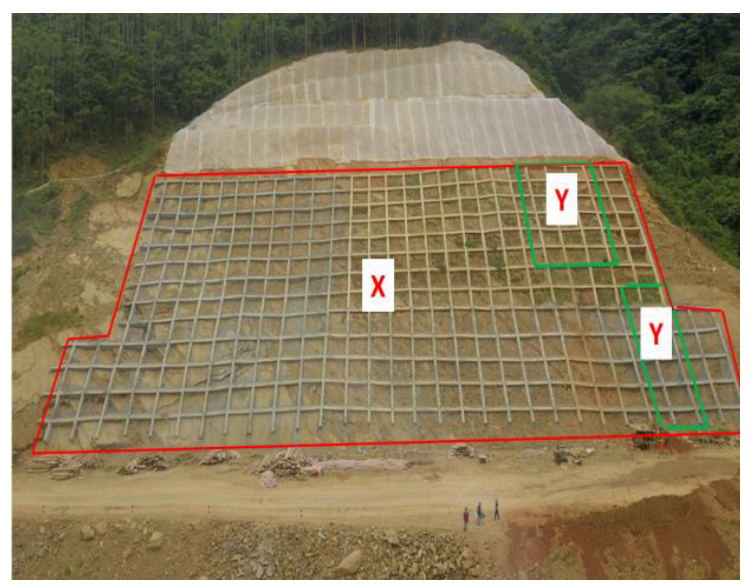

Fig.2 Real shots of the test area

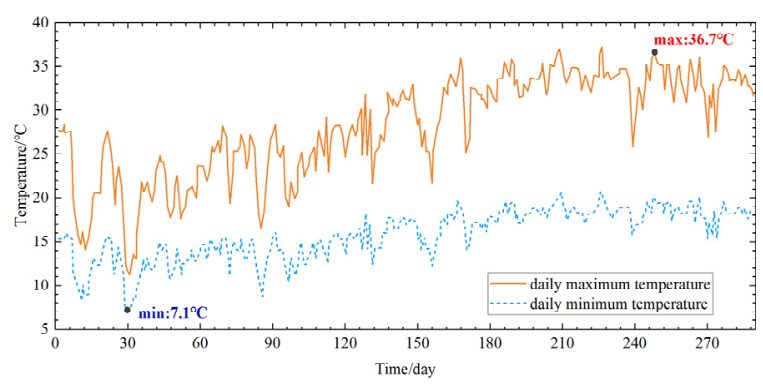

Fig.3 Changes in field temperature during the test

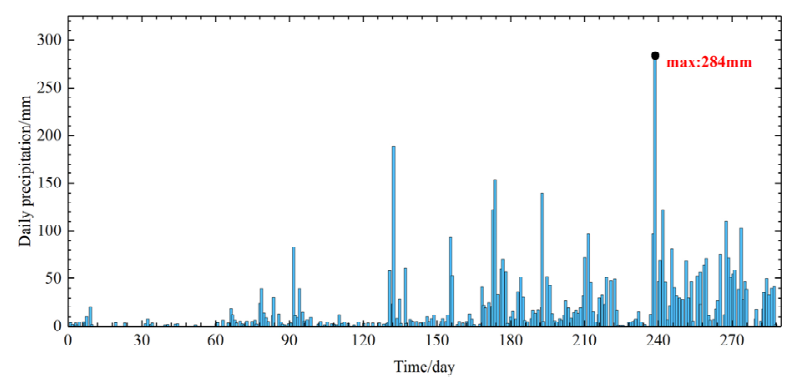

Fig.4 Site precipitation during the test

\subsection{Experimental vegetation}

In combination with the actual climatic conditions of the project site, the experiment used 2 kinds of herbs (molasses, alfalfa), 2 kinds of shrubs (carberry, pigeon pea) and 1 small tree (Leucaena) for ecological restoration. 
(1) Molasses

Molasses Grass is a perennial herb. It is often used as a pioneer plant on newly reclaimed land with a height of about 1 meter.

(2) Medicago Linn

Medicago Linn is an annual or perennial herb with a height of $30 \sim 100 \mathrm{~cm}$ and strong roots. It is an important forage plant and is widely introduced and cultivated all over the world.

(3) Dodonaea viscosa

Dodonaea viscosa is a shrub or small tree with a height of 1-3 meters or higher. It is distributed in tropical and subtropical regions all over the world.

(4) Leucaena leucocephala

Leucaena leucocephala is a shrub or small tree with a height of 2-6 meters, which is produced in Fujian, Guangdong, and it is now widely distributed Various tropical regions.

(5) Cajanus cajan

Cajanus cajan is an upright shrub, 1-3 meters, produced in Yunnan, Sichuan, Jiangxi, Hunan, Guangxi, Guangdong, Hainan, Zhejiang, Fujian, Taiwan, Jiangsu. It is generally cultivated in subtropical regions and is extremely resistant to barren and drought.

\subsection{Test procedure}

The ecological restoration field test of the residual soil slope in South China is mainly composed of three stages: construction preparation phase, slope vegetation protection project construction and slope vegetation maintenance. The main steps of the test are: (1) Slope finishing, (2) Test and lofting, (3) Plant preparation, (4) Preparation of construction materials, (5) Hanging net, (6) Spray substrate mixture, (7) Heat preservation and moisturizing, (8) Slope vegetation maintenance.

\subsection{Test results}

\subsubsection{Overall vegetation restoration}

After the construction, the recovery status of the slope at different times is shown in Fig.5.

The vegetation on the slope began to sprout 15 days after the completion of the construction, and about 30 days after the completion of the construction, the herbaceous plants for the slope protection began to sprout, and the plant heights were mostly between 1 and $5 \mathrm{~cm}$. About 150 days after the completion of the construction, the herb plants have basically grown and covered the slope with a high coverage. At the same time, there are scattered shrubs such as pigeon peas and mulberry among the various grids. But at this time, the germination rate and plant height of the shrub vegetation are low. Therefore, at this time, the slope vegetation is still dominated by vegetation such as alfalfa and molasses, while the shrub vegetation coverage rate is low. 210 days after the completion of the construction, it is obvious that the herbaceous vegetation has declined and its coverage has been greatly reduced. The height of the shrub vegetation has reached $20-50 \mathrm{~cm}$, and the growth status is good. Each frame of the lattice structure is basically distributed with $1 \sim 2$ shrub vegetation.
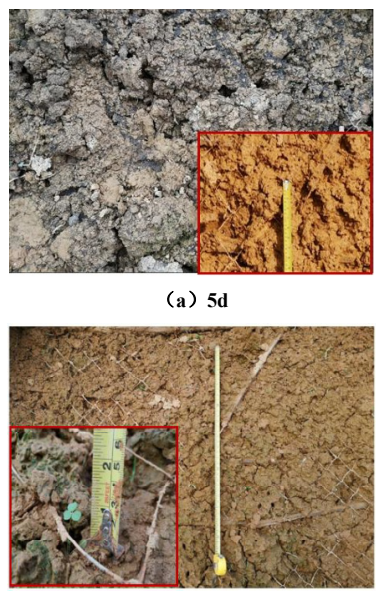

(c) 30d

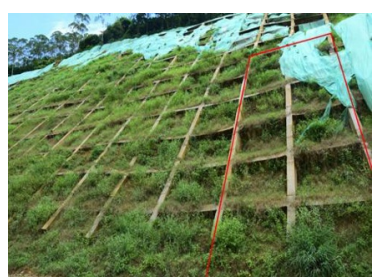

(e) $210 \mathrm{~d}$

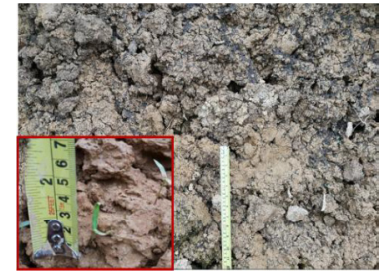

(b) 15d

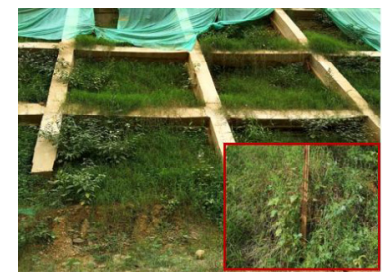

(d) $150 \mathrm{~d}$

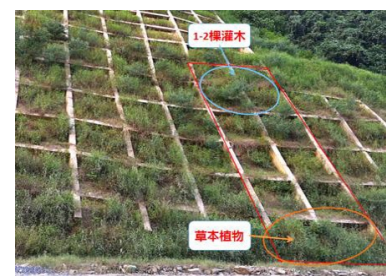

(f) $270 \mathrm{~d}$

Fig.5 The vegetation restoration status on the slope at different times

\subsubsection{Comparative analysis of growth and development of different vegetation}

The change of the plant height of Molasses grass over time is shown in Fig.6. The plant height of Molasses grass reached about $2 \mathrm{~cm}$ after the completion of the construction, about $3.5 \mathrm{~cm}$ at 45 days, and about $15 \mathrm{~cm}$ after 90 days. Molasses grow densely and have a high coverage rate, and grow faster even on slopes where no functional materials are added.
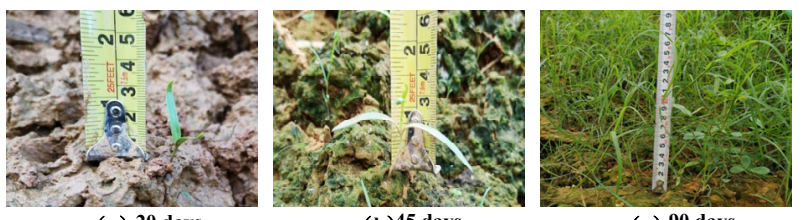

(a) 20 days (b) 45 days

(c) 90 days

Fig.6 Growth of molasses grass in different periods

The change of the height of Medicago Linn with time is shown in Fig.7. The height reaches about $2.2 \mathrm{~cm}$ in about 20days after construction, about $5.5 \mathrm{~cm}$ in 45 days, and about $12 \mathrm{~cm}$ in 90days. Medicago Linn has a low coverage rate per plant, will not inhibit the growth of shrubs, and is conducive to long-term ecological protection. 


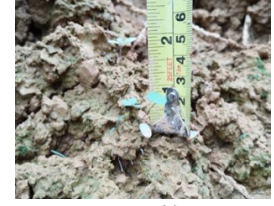

(a) 20 days

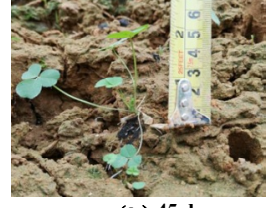

(b) 45 days

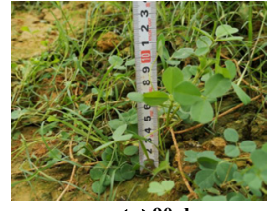

(c) 90 days
Fig.7 Growth of Medicago Linn in different periods

In addition, the growth period of the plant height changes of the two herb plants of Molasses and Medicago Linn and the two shrubs of Cajanus cajan and Dodonaea viscosa are shown in Figure 8 after statistics. It can be seen from the figure that about 20 days after the completion of the construction, all plant species begin to germinate, and the plant height is between $2 \sim 10 \mathrm{~cm}$. Subsequently, with the increase of time, the plant height continued to increase, but the growth rate of the plant height of the two vegetations of Molasses and Medicago Linn slow down after 150 days, and then stabilize and stop growing. The maximum plant height of Molasses is about $24 \mathrm{~cm}$, while the maximum plant height of Medicago Linn is about $20 \mathrm{~cm}$. For shrubs, the plant heights of Cajanus cajan and Dodonaea viscosa have been increasing over time, and the growth trend has not stopped at 250 days. At the 250 th day, their plant heights reached $20 \mathrm{~cm}$ and $80 \mathrm{~cm}$, respectively.

The test results show that within 60 days after the construction, Dodonaea viscosa has the largest growth rate, about $0.37 \mathrm{~cm} / \mathrm{d}$, followed by molasses and Medicago Linn, about $0.13 \mathrm{~m} / \mathrm{d}$, and finally Cajanus cajan, with a growth rate of about $0.1 \mathrm{~cm} /$ day. The results show that in the early stage of slope ecological restoration, Molasses and Medicago Linn two low herbaceous plants can quickly cover the slope and play a major role in strengthening the slope. The growth rates of the two are similar, while the growth rate of Dodonaea viscosa is higher, but the seed germination rate is low, the coverage area is low, and the contribution to the stability of the shallow guest soil is limited.

With the increase of time, the growth of herbaceous plants began to stagnate in the middle and late stages of the conservation phase, and their plants reached the maximum value in the year, and the corresponding protective effect on shallow slopes also reached the maximum. The growth of shrub vegetation is still going on, and its growth rate is relatively high. At this time, the contribution of shrub vegetation to the stability of shallow slopes and resistance to runoff erosion will gradually increase. Therefore, shrub vegetation is an important source for improving the slope water and soil conservation ability in the middle and later stages of maintenance.

At the same time, it should also be noted that the growth rate of Cajanus cajan is always low in the first, middle and late stages of the curing stage, and its average growth rate in the first 200 days is only $0.09 \mathrm{~cm} / \mathrm{d}$. Indicating that its growth has not reached the ideal value. The reason for this phenomenon may be that the proportion of herb seeds is relatively high, and the early herb plants germinate and cover quickly. The growth of herb plants absorbs a large amount of nutrients in the soil, and at the same time, it affects the slope surface due to the sheltering effect. The moisture and heat transfer in the soil ultimately affect the germination and growth of Cajanus cajan.

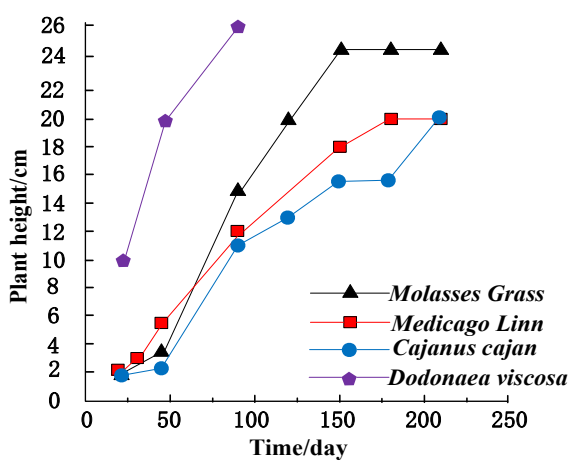

Fig.8 Variation curve of plant height with time in different vegetation growth periods

\section{Conclusion}

Based on the principle of local conditions, a study on vegetation selection for ecological restoration of residual soil slopes in South China has been carried out. The main conclusions are as follows:

(1) The high-temperature and high-humidity conditions in the mountainous areas of South China cause differences in the selection of vegetation in the slope ecological restoration project in this region from other regions. The vegetation selection should be based on warm-season vegetation that prefers warm and humid conditions.

(2) The main growth period of herbaceous plants is in the early stage of the slope protection engineering, and its growth stagnates in the middle and late stages. Adding shrubs, small trees and other middle and later plants will help further improve the erosion protection ability of the slope in the middle and later stages.

(3) When using a mixed spray of multiple plants, the proportion of different plants should be determined according to the growth cycle of different plants and the results of the indoor ratio test, so as to avoid the influence of the shading effect that inhibits the growth of some species.

\section{Acknowledgement}

Pearl Rover S\&T Nova Program of Guangzhou(2019060 10068).

\section{References}

1. Zhang Junyun, Zhou Depei, Li Shaocai. Discussion on greening methods of highway rock slopes[J]. Chinese Journal of Rock Mechanics and Engineering, 2002, 21 (09): 1400-1403.

2. Zhang Junyun, Zhou Depei. Study on plant selection and design of thick-layer substrate spraying 
vegetation for slope protection[J]. Journal of Soil and Water Conservation, 2002, 16 (04): 163-165.

3. Yang Jianxin, Li Faju. Research on greening measures and plant selection of rock slopes in North China[J]. Roadbed Engineering, 2012 (05): 51-55.

4. Kong Donglian. Study on the selection of greening plants on the road side slope in Mentougou District [D]. Beijing: Beijing Forestry University, 2007.

5. Chen Ximin. Application of grass planting technology in subgrade slope protection[J]. Roadbed Engineering, 1999 (01): 17-19.

6. Xie Yalin, Wang Xiaolin. Grass species and construction methods of biological protection engineering of southern expressway $[\mathrm{J}]$. Grassland and Lawn, 2000 (1): 37-39.

7. Liu Derong, Ma Yonglin, Han Liebao, et al. The selection of greening grass species and combinations on slope surface hydraulic spraying $[\mathrm{J}]$. Journal of Beijing Forestry University, 2000, 22 (02): 41-45.

8. Wei Tao. Highway slope ecological protection engineering system and the choice of slope protection vegetation[J]. Highway Traffic Technology, 2000 (1): 12-15.

9. Guo Xiaorong, Jiang Yulin, Long Chunlin, et al. Preliminary study on protective plants for highways in central Yunnan [J]. Journal of Mountain Research, 2000, 18 (02): 115-121.

10. Wu Yanqi, Yang Lie, Xu Xiaogang, et al. Discussion on the climate division of lawn planting in Sichuan[J]. Acta Grassland, 2000, 08 (01): 8-12.

11. Ma Haitiancai, Liao Xinbei, Tan Yanhe, et al. Research on the mixed planting ratio of grass seeds for ecological protection of rock slopes[J]. Roadbed Engineering, 2003 (05): 73-75.

12. Zheng Yuji, Zhuo Muning, Li Dingqiang, et al. Application of mixed grass and shrub in slope greening protection[J]. Ecological Environment, 2007 (01): 149-151.

13. Yu Xiaohua, Jiang Yulin, Liu Rongtang. Quantitative analysis of the adaptability of grass species on highway slopes[J]. Journal of Zhongkai University of Agriculture and Technology, 2002, 15 (03): 33-38.

14. Zhang Chunlin, Zhang Hongjiang, Jiang Yulin, et al. Research on soil erosion characteristics and soil conservation benefits of highway embankment slopes[J]. Research on Soil and Water Conservation, 2007, 14 (03): 367-370.

15. Liu Wenzhu, Zhou Jian, Cai Jingru, et al. Research on plant niche for restoration of exposed slopes in South China[J]. Bulletin of Soil and Water Conservation, 2017, 37 (2): 215-221. 